\title{
Interface Detection of Concrete and Slurry in Cast-in Place Pile
}

\author{
Zhaolei $\mathrm{Liu}^{1}$, Lei $\mathrm{Yu}^{2, *}$, and Shuxiong Zhang ${ }^{2}$ \\ ${ }^{1}$ Research institute of highway ministry of transport, No.8 yard, Xi tu cheng Road, Hai-dian district, Beijing, China. \\ 2 Beijing Xin-Qiao Technology Development Co., LTD, No.8 yard, Xi tu cheng Road, Hai-dian district, Beijing, China
}

\begin{abstract}
To find the interface of concrete and slurry in a cast-in place pile, the numerical simulation method and Laboratory tests are performed. Pressures along a pipe were obtained. Differential pressures of fixed distance were calculated. Differential pressure curves were plotted. The result shows that pressure along a pipe is differ. Differential pressure remains constant in certain mediums but changes across different mediums. The interface of concrete and slurry can be found from differential pressure plots. If transducers whose number is at least two can be tied on a fixed place of pipe, differential pressure will be obtained by pulling pipe out gradually, and the interface of the concrete and slurry will be found easily. This is useful for keeping pipe under concrete and ensuring pipe quality.
\end{abstract}

\section{Introduction}

The cast-in place pile is part of underground construction. Pipe is used for pouring concrete into a pile hole [1]. Every pouring reaches a depth of 6 meters, at which point the pipe must be lifted. To make pouring continuous, the pipe must be kept in concrete at a depth of at least 2 meters [2]. Therefore, pipe depth control is necessary. If a pipe is pulled out of concrete, the pile will be separated into two parts [3]. Currently, people always use a drop-hammer to detect the top of the concrete [4]. This method is manual and inefficient because pouring progress has to be stopped. To find the interface of concrete and slurry in cast-in place pile in a timely way, differential pressure was measured by numerical simulation and laboratory tests.

\section{Material and methods}

\subsection{Numerical simulation}

ICEM CFD 16.0 is used to build the geometric model and mesh generation. Fluent 16.0 is used to build the fluid numerical calculation model. Tecplot 360 EX 2015 R1 software is used for numerical calculation result reduction.

\subsubsection{Geometric model abstracted}

During pouring, the pipe will be lifted when its bottom is 6 meters beneath the concrete. This is a cyclic process. In certain construction projects, sizes such as the diameter of pile holes, pipe diameters and pipe wall thicknesses are fixed. Investigation shows that the diameter of pile hole is usually 1.2 meters. Pipe diameters are usually 30 centimeter. Pipe wall thicknesses are 8 millimeter. The geometric model of a pouring system can be abstracted as the following figure.

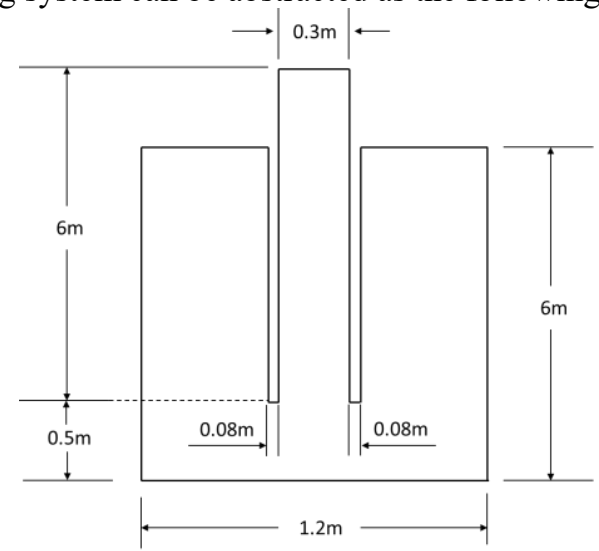

Fig. 1. Sketch map of geometric model of cast-in place pile system

\subsubsection{Mesh generation}

Mesh generation steps are shown as the following figures.

\section{Step 1 Geometric graph drawing}

The point on left bottom is $(0,0,0)$. Define coordinates as shown in Table 1. Fig. 2 is a sketch map of a geometric graph.

Table 1. Coordinates list for every point

\begin{tabular}{|c|c|c|c|c|}
\hline Point & 1 & 2 & 3 & 4 \\
\hline Coordinate & $0,0,0$ & $1.2,0,0$ & $1.2,6,0$ & $0.758,6,0$ \\
\hline Point & 5 & 6 & 7 & 8 \\
\hline Coordinate & $0.758,0.5,0$ & $0.75,0.5,0$ & $0.75,6.5,0$ & $0.45,6.5,0$ \\
\hline Point & 9 & 10 & 11 & 12 \\
\hline Coordinate & $0.45,0.5,0$ & $0.442,0.5,0$ & $0.442,6,0$ & $0,6,0$ \\
\hline
\end{tabular}




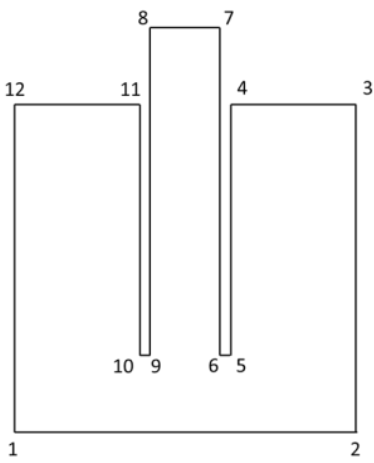

Fig. 2. Sketch map of geometric graph

Fig. 3 is a drawing by ICEM and it is the real geometric graph. The pipe wall is very thin.

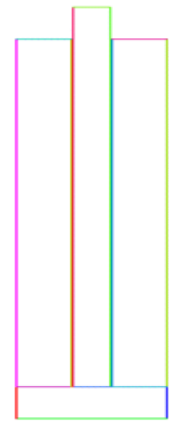

Fig. 3. Real Geometric graph

\section{Step 2 Surface created}

Divide geometric graph into some rectangle regions and then create surface. Divided results are shown as Figure 4.

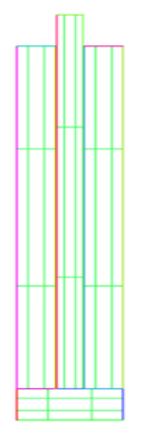

Fig. 4. Surface created

\section{Step 3 Created Part}

As shown as Fig. 2, define 7-8 as the fluid enters face. Define 3-4 as the fluid outflow face 1 and 11-12 as fluid outflow face 2 .

\section{Step 4 Created Block}

Select the structured grid; the blocks need to be created. Using 2D Planer, by means of split block, create some regular square blocks. Delete the surplus blocks.

\section{Step 5 Define mesh parameter}

Define global grid 0.01 . The node numbers of each edge list are in Table 2.
Table 2. List of node numbers

\begin{tabular}{|c|c|c|c|c|c|c|}
\hline Edge & $7-8$ & $8-16$ & $7-15$ & $11-12$ & $3-4$ & $12-13$ \\
\hline $\begin{array}{c}\text { Node } \\
\text { number }\end{array}$ & 20 & 30 & 30 & 30 & 30 & 220 \\
\hline Edge & $11-10$ & $16-9$ & $15-6$ & $4-5$ & $3-14$ & $13-1$ \\
\hline $\begin{array}{c}\text { Node } \\
\text { number }\end{array}$ & 220 & 220 & 220 & 220 & 220 & 30 \\
\hline edge & $2-14$ & $9-10$ & $6-5$ & $/$ & $/$ & $/$ \\
\hline $\begin{array}{c}\text { Node } \\
\text { number }\end{array}$ & 30 & 6 & 6 & $/$ & $/$ & $/$ \\
\hline
\end{tabular}

Step 6 Generate the grid

Generate the grid and save the grid file.

\subsubsection{Simulation model abstracted}

When pouring, there are two kinds of fluid. One is concrete, and the other is slurry. Concrete is poured into pipe and falls on the slurry. The slurry is pushed out the pile hole by the concrete. Actually, concrete and slurry are independent. There is an interface between concrete and slurry. Volume of Fluid model [5] is suitable for this kind of flow.

\subsubsection{Simulation and parameters set}

Simulation steps and the parameters set are made as follows.

\section{Step 1 Dimension selected}

On the start board, select the 2D button, and keep the other button as the default.

\section{Step 2 Read and check grid}

Read the grid and check it. Make sure the minimum volume and minimum area are not negative.

\section{Step 3 Set solver parameters}

(1) Select gravity. Input -9.8 under the $\mathrm{Y}$ coordinate box. Set the time as transient.

(2) In the model plate, select K-epsilon (2eqn) in the drop-down list of Viscous-Laminar. Keep the other selections as the default.

(3) In the material plate, double-click air, and modify the parameters as slurry. Slurry density is 1300 $\mathrm{kg} / \mathrm{m}^{3}$. The dynamic viscosity of slurry is $2.5 \mathrm{~kg} / \mathrm{m}-\mathrm{s}$. Repeat double-click air, and modify the parameters as concrete. Concrete density is $2400 \mathrm{~kg} / \mathrm{m}^{3}$. The dynamic viscosity of concrete is $15 \mathrm{~kg} / \mathrm{m}-\mathrm{s}$.

(4) In the model plate, select the VOF (Volume of Fluid) model. Tick Implicit Body Face under Body force formulation. Set the number of Eulerian phases as 2 .

(5) Double click primary phase, and set slurry as the main phase. Double click secondary phase, and set the second phase as concrete.

(6) In boundary conditions, set the entrance as velocity. Fluid select concrete. Input flow velocity as $0.1 \mathrm{~m} / \mathrm{s}$. In the edit window, set the volume fraction in multiphase as 1 . This means concrete pushes out slurry rather than being injected into it. Select the entrance phase as mixture. Set it as velocity, and keep the other set as default. Select entrance phase as slurry. Set it as velocity, and keep the other set as default. Select mixture for exit and set it as outflow. 
Select mixture for wall, and set it as wall. Set geometry wall and its shadow as interior.

(7) In the solution control plate, input 0.3 in the momentum box. Input 0.5 in the boxes for turbulent kinetic energy and turbulent dissipation rate.

(8) In the solution initialization plate, input 0.001 in the boxes for turbulent kinetic energy and turbulent dissipation Rate. Click initialization.

(9) In the calculation activities plate, input 30 in auto save every box.

(10) In run calculation, input 1 in the time step size box and input 600 in number of time steps box. This means the flow will continue for ten minutes.

(11) Save the calculation file.

(12) In the run calculation plate, click calculation.

\subsection{Laboratory test}

\subsubsection{Simulation and parameters set}

To simulate pouring progress and obtain differential pressure, two pressure transducers were tied on the bottom of a steel stick as shown in the Fig. 5. The transducer type is Series $26 \mathrm{Y}$. the transducer trademark is Keller. $26 \mathrm{Y}$ transducers are analog signal ones. They can output the electricity value. The measuring range is from $0 \mathrm{~mA}$ to $20 \mathrm{~mA}$. The distance between two transducers is approximately 30 centimeters.

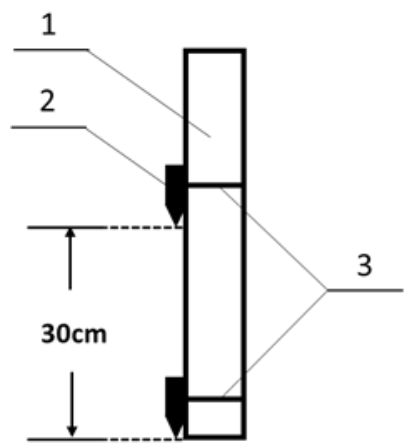

1. Stick 2. Transducer 3. Bundling device

Fig. 5. Transducers arrangement form

\subsubsection{Cast-in place pile pouring simulation}

A PVC pipe was used to simulate a pile hole. The diameter of PVC pipe is 20 centimeters. The height of PVC pipe is 120 centimeters. The PVC pipe and sticker with transducers compose the pouring simulation system.

Put the stick with transducers into the PVC pipe and then pour concrete and slurry into the PVC pipe in turn. Pull the stick out 10 centimeters at a time. Pressure along the PVC pipe will be obtained. Positions of the stick for different heights of PVC pipe are shown in Fig. 6.

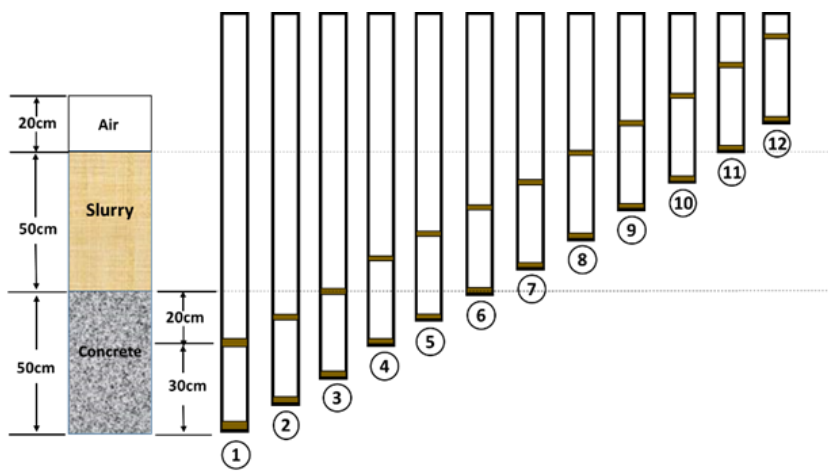

Fig. 6. Positions of stick in pipe

\section{Results}

\subsection{Interface finding by numerical simulation}

To find the interface and observe differential pressure changing rules, you can select any pouring time to analyse. For example, select $120 \mathrm{~s}$ as an example. Pressure along the pipe can be read as shown in Table 3. Below the date minus the above one, differential pressure can be obtained.

Table 3. Pressure in pipe

\begin{tabular}{|c|c|c|}
\hline $\begin{array}{c}\text { Depth from pipe } \\
\text { bottom } / \mathrm{cm}\end{array}$ & $\begin{array}{c}\text { Absolutely } \\
\text { pressure } / \mathrm{Pa}\end{array}$ & $\begin{array}{c}\text { Differential } \\
\text { pressure/Pa }\end{array}$ \\
\hline 0 & 98200 & $/$ \\
\hline 30 & 91000 & 7200 \\
\hline 60 & 83800 & 7200 \\
\hline 90 & 76600 & 7200 \\
\hline 120 & 69400 & 7200 \\
\hline 150 & 62200 & 7200 \\
\hline 180 & 55000 & 7200 \\
\hline 210 & 47800 & 7200 \\
\hline 220 & 42900 & 3900 \\
\hline 250 & 39000 & 3900 \\
\hline 280 & 35100 & 3900 \\
\hline 310 & 31200 & 3900 \\
\hline
\end{tabular}

Differential pressure is plotted in Fig. 7. 220 centimeters is a demarcation point. Under 220 centimeters, there is concrete around the pipe. Every other 30 centimeters, differential pressure remains constant. Over 220 centimeters, there is slurry around the pipe. Every other 30 centimeters, differential pressure remains constant at another level. At the 220 centimeter point, differential pressure changes suddenly. Therefore, 220 centimeters above the pipe bottom is the interface of concrete and slurry. 


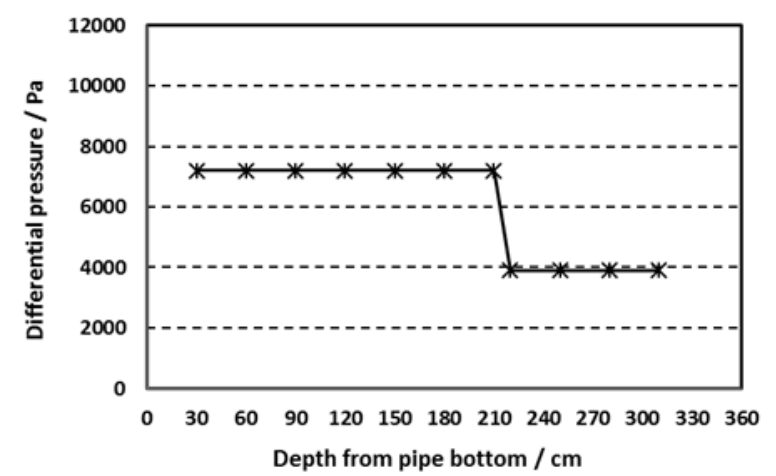

Fig. 7. Differential pressure along pipe by simulation

To support the result that 220 centimeters is the demarcation point of concrete and slurry, the phase of concrete at $120 \mathrm{~s}$ is exported as shown in Fig. 8.

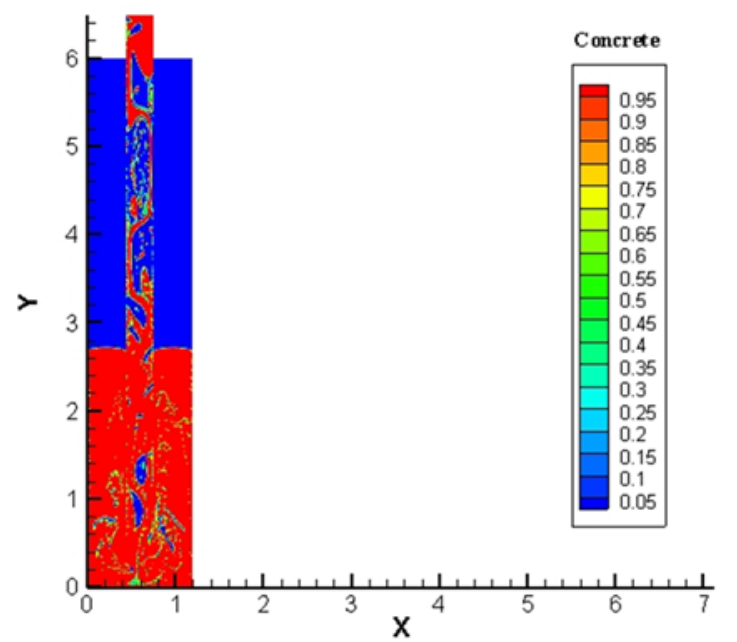

Fig. 8. Phase of concrete in 120

From Fig. 8, at a time of 120 s, the interface of concrete and slurry is at a 220 centimeters depth from the pipe bottom. This phase picture supports the Fig. 7 result.

We make the assumption that if we tie some pressure transducers every 30 centimeters along the pipe, pressure can be obtained and the differential pressure figure can be plotted as in Fig. 8. From the differential pressure figure, we can read the interface location of the concrete and slurry.

\subsection{Interface finding by Laboratory test}

Electricity is detected by pressure transducers on the pipe. Pressure Value and differential pressure are calculated and shown in Table 4.

Table 4. Electricity value recorded by transducers and pressure calculated

\begin{tabular}{|c|c|c|c|c|c|}
\hline \multirow[b]{2}{*}{$\begin{array}{l}\text { Position } \\
\text { ID }\end{array}$} & \multicolumn{2}{|c|}{ Electricity } & \multicolumn{2}{|c|}{ Pressure } & \multirow[b]{2}{*}{$\begin{array}{c}\text { Differential } \\
\text { pressure }\end{array}$} \\
\hline & $\begin{array}{l}\text { Upper } \\
\text { transducer }\end{array}$ & $\begin{array}{c}\text { Below } \\
\text { transducer }\end{array}$ & $\begin{array}{c}\text { Upper } \\
\text { transducer }\end{array}$ & $\begin{array}{c}\text { Below } \\
\text { transducer }\end{array}$ & \\
\hline 1 & 11.73 & 15.91 & 24.48 & 37.71 & 13.24 \\
\hline 2 & 10.51 & 14.7 & 20.61 & 33.88 & 13.27 \\
\hline 3 & 9.38 & 13.58 & 17.04 & 30.33 & 13.30 \\
\hline 4 & 8.27 & 12.12 & 13.52 & 25.71 & 12.19 \\
\hline 5 & 7.17 & 10.67 & 10.04 & 21.12 & 11.08 \\
\hline 6 & 6.11 & 9.37 & 6.68 & 17.00 & 10.32 \\
\hline 7 & 4.99 & 8.25 & 3.14 & 13.46 & 10.32 \\
\hline 8 & 4.02 & 7.25 & 0.06 & 10.29 & 10.23 \\
\hline 9 & 4.02 & 6.18 & 0.06 & 6.90 & 6.84 \\
\hline 10 & 4.02 & 5.12 & 0.06 & 3.55 & 3.48 \\
\hline 11 & 4.02 & 4.02 & 0.06 & 0.06 & 0 \\
\hline 12 & 4.02 & 4.02 & 0.06 & 0.06 & 0 \\
\hline
\end{tabular}

Differential pressure is plotted as shown in Fig. 9. 


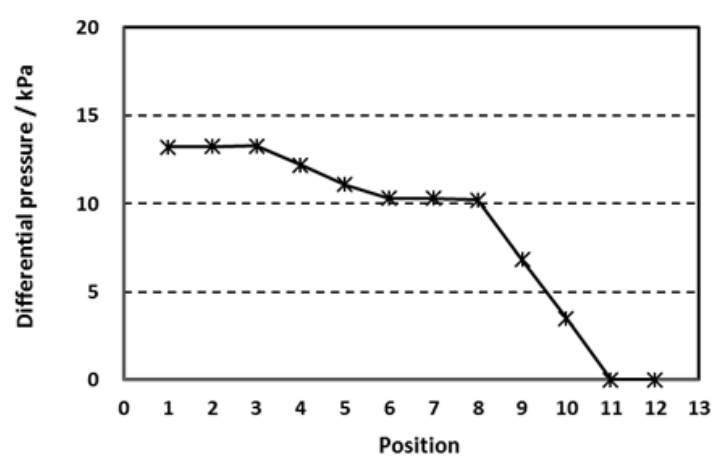

Fig. 9. Differential pressure along pipe by lab test

As shown in Fig. 9, from position 1 to position 3, two transducers are all in concrete and differential pressure remains constant. From position 4 to position 6 , the upper transducer is pulled out of the concrete and into the slurry; differential pressure is changed. From position 7 to position 8 , two transducers are all in the slurry; differential pressure remains constant at a new level. From position 9 to position 11, the upper transducer is pulled out of the slurry and into the air, differential pressure is changed. After position 11, two transducers are all in the air, differential pressure is almost zero.

Also from Fig. 9, the interface of concrete and slurry can be found, and it is position 3 . The interface of slurry and air can be found, and it is position 8 .

\section{Discussion}

By means of detecting pressure along the pipe, differential pressure can be calculated and plotted. From the differential pressure figure, the interface of concrete and slurry can be found. This interface is very important. If the bottom of the pipe is pulled out of this interface, the pile will be separated into two parts. A two parts pile is below construction standard and will be discarded. This causes financial loss. By means of pressure detecting, keeping the pipe in the concrete is good for quality control in cast-in place pile construction.

\section{Conclusions}

Numerical simulation and laboratory tests are performed to find the interface of concrete and slurry in the cast-in place pile.

Numerical simulation results show that pressure is changing by depth of pipe. In the same medium, differential pressure remains constant for fixed distances. When the interface of two different mediums is stepped over, differential pressure will change immediately.

Laboratory test results show that pressure is changing by depth of stick. Pressure will change when the transducer is pulled out from the concrete and into the slurry. For fixed distance, differential pressure remains constant in the concrete or in the slurry. However, the values in the concrete or in slurry are different. The constant in slurry is lower than that in concrete. When the upper transducer is pulled out of the concrete, the differential pressure changes, and this can be observed in the figure. The interface of concrete and slurry can be found in the differential pressure plot.

Laboratory test results support numerical simulation results. Therefore, by means of setting the transducer on the pipe at fixed distance, pressure can be detected, and a differential pressure plot can be obtained. From the differential pressure plot, the interface of concrete and slurry can easily be found. It can be used to prevent the occurrence of pipe pull out from concrete and ensure the quality of cast-in place pile construction.

\section{Acknowledgements}

Thank you Lei Chen for helping with my lab test. Thank you LIU Zhao-lei for proofreading this paper.

This work was supported by the Basic Research Found for National Public Welfare Scientific Research Institutions [grant numbers 2015-9034] and the Ministry of Communications and Enterprise Innovation Item [grant numbers 2015315 Q13 040].

\section{References}

1. Z.Miao, Zhang. Pile Foundation Project. (China Building Industry Press, 2007) (In Chinese)

2. G.Qing Zhang, L,Yu, Z.Lei Liu. Journal of Highway Communication technology,2,3(2017) (In Chinese)

3. S.Cai Ding. Journal of Highway.3,4(2015) (In Chinese)

4. H.Cheng Ding. Guangxi Normal University Journal.31,3(2010)( In Chinese)

5. J.Peng Kang. Ansys Fluent 16.0 Super Study Notebook. (Posts and Telecom Press, 2016) (In Chinese) 